\title{
A comparison of Oral and Inhalant Corticosteroids in Treatment of Mild to Moderate Asthma Exacerbation in Children
}

Nemat Bilan ${ }^{1}$, Lida Saboktakin ${ }^{1}$, Masoumeh Ghasempour ${ }^{{ }^{*}}$

1. Pediatric Health Research Center, Tabriz University of Medical Sciences, Tabriz, Iran

\begin{abstract}
Introduction: Oral corticosteroids are the main treatment in asthma exacerbation. It has been reported that inhaled corticosteroids can be used instead of oral corticosteroids in asthma exacerbation. We aimed to evaluate the efficacy of inhaled fluticasone and oral prednisolone in children with mild to moderate asthma exacerbation.

Materials and Methods: In this randomized clinical trial, 60 children with mild-to-moderate acute asthma exacerbation visiting emergency department were randomly assigned to receive oral prednisolone $(2 \mathrm{mg} / \mathrm{kg}$ ) or fluticasone spray ( 2 puffs every 12 hours, each puff contains 250 microgram fluticasone) using an spacer for one week. The first dose of the treatment was given in the emergency department. Children were followed for seven days and signs and symptoms of exacerbation, as well as spirometry findings were evaluated.

Results: On the days 1 and 3, symptoms including cough, sputum and need for salbutamol during day was more improved in oral prednisolone and symptoms at night was more improved in inhaled fluticasone. Patients were almost symptom free on the seventh day. Forced expiratory volume in 1 second, forced vital capacity and forced expiratory flow rate on the seventh day were significantly better with inhaled fluticasone compared to oral prednisolone.

Conclusion: Both inhaled fluticasone and oral prednisolone improved symptoms during a week after exacerbation; however, better respiratory function in children treated with inhaled fluticasone is indicative of its further efficacy compared to oral prednisolone. Considering the low systemic effects of inhaled fluticasone, this treatment seems to be more appropriate in treatment of mild to moderate exacerbations.
\end{abstract}

Keywords: Asthma exacerbation; Inhaled fluticasone; Prednisolone

\section{Introduction}

Asthma is one of the most common chronic diseases in children worldwide. Asthma is characterized by chronic airway inflammation, impaired pulmonary function, and episodic

respiratory symptoms $(1,2)$. Asthma is the most prevalent childhood chronic disease requiring emergency department (ED) visits due to its exacerbation $(3,4)$. Treatment of asthma

\section{Corresponding author:}

Masoumeh Ghasempour

Tabriz Children's Hospital, Sheshgelan St, Tabriz, Iran

Tel: +984115262280 Fax: +984115262280 E-mail: masoumeh_gh_a@yahoo.com

Receive date: 2014-08-19| Accept date: 2014-09-05| Publish date: 2014-09-29

DOI: 10.7575/aiac.abcmed.15.03.02.03 
exacerbations includes early recognition and initiation of therapy with bronchodilators and anti-inflammatory corticosteroids. Inhaled rapid-acting $\beta 2$ agonist (salbutamol) is the standard treatment for acute exacerbation especially in young children (5-7). The use of systemic steroids is recommended in patients with acute asthma exacerbations who fail to respond promptly or completely to short-acting $\beta$-agonist therapy (8). Early administration of oral corticosteroids can reduce airway inflammation, improve normalization of lung function, decrease rates of hospitalization, and decrease the number of repeat visits to the ED (9-12).

Despite beneficial effects of oral corticosteroids, patients' compliance to drug use after discharge from emergency department is low because of prolonged course of therapy and potential unpleasant side effects (13-16). Due to the decreased compliance and acceptance to oral corticosteroid use, it is important to find some other possible alternatives. Nowadays, inhaled corticosteroids are used as treatment choice in chronic asthma (17-21), and it is possible to be used in mild to moderate exacerbation of asthma. It is shown that oral corticosteroids (OCS) compared to inhaled corticosteroids (ICS) are more effective in severe asthma exacerbation $(22,23)$. However, studies evaluating the role of inhaled corticosteroids in treating patients with mild to moderate exacerbation of asthma reported some conflicting results (24-29).

In this study, we aimed to evaluate the efficacy of oral and inhalant corticosteroids in treatment of mild to moderate asthma exacerbation in children.

\section{Materials and methods}

In this randomized clinical trial, 60 children with mild-to-moderate acute asthma exacerbation visiting emergency department, Tabriz Children's hospital, Iran between May
2012 and January 2014 were studied. Inclusion criteria were children between 5-14 years old with a documented diagnosis of asthma for $\geq 6$ months, with mild-to-moderate acute asthma exacerbation with baseline FEV1 $50 \%$ to $79 \%$ predicted. Exclusion criteria were children with persistent vomiting, airway instability, treatment with oral corticosteroids within 7 days, coexistent heart, liver, kidney and chronic pulmonary diseases, cardiopulmonary/neuromuscular disease, and severe exacerbation requiring intensive care or mechanical ventilation or previous treatment in the intensive care unit for asthma. We also excluded patients with any contraindications to use salbutamol. The study has been approved by the ethical committee of Tabriz University of Medical Sciences and informed written consents were obtained from all patients or their guardians, controls and their parents before including in the study.

In the emergency department, both groups received 02 therapy and salbutamol 2 puffs each 20 minutes until the symptoms were controlled. Patients were randomly assigned to two treatment groups using Randlist software. First group was treated with salbutamol spray (2 puffs every four hours for 48 hours, each puff contained 100 micro grams of the drug) using an spacer plus oral prednisolone (2 milligrams/Kg for one week). Second group was treated with salbutamol spray (2 puffs every four hours for 48 hours) plus fluticasone spray ( 2 puffs every 12 hours, for one week, each puff contained 250 micrograms of the drug) using an spacer. The first dose of the treatment (oral prednisolone or fluticasone spray) was given in the emergency department. Children were followed on days one, third and seven for any signs and symptoms of exacerbation. Spirometry was performed in these periods to evaluate Forced expiratory volume in one second (FEV1), forced vital capacity (FVC), FEV1/FVC and forced expiratory flow (FEF) 25- 
75\%. Children with persistent symptoms during study were referred either to our emergency department or to their physicians for assessment. Peak flowmetry was also performed using peak flow meter to measure the flow of air as it is expelled from the lungs and lung function.

\section{Statistical analysis}

Statistical analyses were performed using the Statistical Package for Social Sciences, version 17.0 (SPSS, Chicago, Illinois). Quantitative data were presented as mean \pm standard deviation (SD), while qualitative data were demonstrated as frequency and percent (\%). The categorical parameters were compared by $\chi 2$ tests, and the continuous variables were compared by independent $t$ test. A $p$ value of $<0.05$ was considered statistically significant.

\section{Results}

Sixty children $(83.3 \%$ male with the mean age of $7.36 \pm 2.09$ years) with mild to moderate asthma exacerbation were evaluated in 2 groups receiving oral prednisolone $(n=30)$ and inhaled fluticasone $(n=30) . \quad$ Table 1 demonstrates baseline findings between groups. Besides being passive smoker which was significantly more in fluticasone group, there was no significant difference between groups in other baseline findings.

Symptoms improvement during the days and nights 1, 3 and 7 after discharge are demonstrated in table 2 . Children receiving oral prednisolone were significantly more cough free and sputum free in day 3 , but in other days there were no significant differences. Comparing the results, it seems that oral prednisolone is more effective in controlling daily symptoms, while inhaled fluticasone is more effective in controlling night time symptoms.

The changes in pulmonary function test were also evaluated before treatment and 7 days after treatment using spirometry (Table 3). Children receiving inhaled fluticasone had significantly better FVC in first day and better FEV1, FVC and FEF in the day 7 after treatment.

\begin{tabular}{cccc}
\hline & $\begin{array}{c}\text { Oral } \\
\text { prednisolone }\end{array}$ & $\begin{array}{c}\text { Inhaled } \\
\text { fluticasone }\end{array}$ & P value \\
\hline Age (years) & $7.73 \pm 2.30$ & $7.00 \pm 1.81$ & NS \\
Gender, male & $26(86.7 \%)$ & $24(80 \%)$ & NS \\
Rhinitis & $2(6.7 \%)$ & $6(20 \%)$ & NS \\
Sinusitis & $10(33.3 \%)$ & $4(13.3 \%)$ & NS \\
Gastroesophageal reflux disease & 0 & $5(16.7 \%)$ & NS \\
Passive smoker & $4(13.3 \%)$ & $11(36.7 \%)$ & 0.03 \\
Previous corticosteroid use & $24(80 \%)$ & $20(66.7 \%)$ & NS \\
Acute asthma exacerbation in the last 2 & $1.53 \pm 0.33$ & $1.34 \pm 0.34$ & NS \\
years & & & \\
\hline
\end{tabular}

Table 1: Baseline findings between groups 


\begin{tabular}{|c|c|c|c|c|}
\hline & & Oral prednisolone & Inhaled fluticasone & $P$ value \\
\hline Cough & Day 1 & 0 & 0 & ---- \\
\hline \multirow[t]{5}{*}{ (symptom free) } & Day 3 & $6(20 \%)$ & 0 & $0.02^{*}$ \\
\hline & Day 7 & $20(66.7 \%)$ & $16(53.3 \%)$ & NS \\
\hline & Night 1 & $10(33.3 \%)$ & 8 (26.7\%) & NS \\
\hline & Night 3 & $22(73.3 \%)$ & 25 (83.3\%) & NS \\
\hline & Night 7 & $28(93.3 \%)$ & $30(100 \%)$ & NS \\
\hline Sputum & Day 1 & $18(60 \%)$ & $14(46.7 \%)$ & NS \\
\hline \multirow[t]{5}{*}{ (symptom free) } & Day 3 & $20(66.7 \%)$ & $11(36.7 \%)$ & $0.03^{*}$ \\
\hline & Day 7 & $28(93.3 \%)$ & $28(93.3 \%)$ & ----- \\
\hline & Night 1 & $22(73.3 \%)$ & $22(73.3 \%)$ & ----- \\
\hline & Night 3 & $24(80 \%)$ & $28(93.3 \%)$ & NS \\
\hline & Night 7 & 30 (100\%) & $30(100 \%)$ & ----- \\
\hline \multirow{6}{*}{$\begin{array}{l}\text { Salbutamol use } \\
\text { (symptom free) }\end{array}$} & Day 1 & $10(33.3 \%)$ & $13(43.3 \%)$ & NS \\
\hline & Day 3 & $22(73.3 \%)$ & $20(66.7 \%)$ & NS \\
\hline & Day 7 & 30 (100\%) & $28(93.3 \%)$ & NS \\
\hline & Night 1 & $8(26.7 \%)$ & $10(33.3 \%)$ & NS \\
\hline & Night 3 & $22(73.3 \%)$ & 25 (83.3\%) & NS \\
\hline & Night 7 & 30 (100\%) & 30 (100\%) & NC \\
\hline
\end{tabular}

Table 2: Symptoms improvement in the first 7 days after discharge

\begin{tabular}{ccccc}
\hline & & Oral prednisolone & Inhaled fluticasone & P value \\
\hline FEV1 & Before & $88.06 \pm 18.81$ & $84.55 \pm 38.45$ & NS \\
& Day 7 & $104.36 \pm 12.62$ & $115.20 \pm 17.19$ & $\begin{array}{c}0.007 \\
*\end{array}$ \\
FVC & Before & $86.16 \pm 17.57$ & $97.16 \pm 17.60$ & $0.01^{*}$ \\
& Day 7 & $104.00 \pm 12.94$ & $114.93 \pm 19.51$ & $0.01^{*}$ \\
FEV1/FVC & Before & $99.83 \pm 9.14$ & $101.76 \pm 6.31$ & NS \\
& Day 7 & $109.66 \pm 14.22$ & $109.53 \pm 8.64$ & NS \\
& Before & $95.66 \pm 35.41$ & $98.66 \pm 23.73$ & NS \\
& Day 7 & $106.96 \pm 13.13$ & $120.06 \pm 18.40$ & 0.002 \\
& & & & $*$ \\
\hline
\end{tabular}


Before

Day 7

Before

Day 7
PEF

$89.96 \pm 34.61$

$125.53 \pm 39.94$

PFM

$136.00 \pm 34.79$

$174.66 \pm 51.97$

$104.63 \pm 35.35$

NS

$123.60 \pm 31.56$

NS

$134.33 \pm 44.61$

NS

$165.66 \pm 47.53$

Table 3: Changes in pulmonary function tests during follow-up period

\section{Discussion}

Children suffering from asthma symptoms present frequently to pediatric emergency departments $(3,4)$. It is well documented that OCS use is effective in alleviating the symptoms of acute asthma exacerbations $(11,12)$. It is also shown that early initiation of oral corticosteroid is associated with reduced times to clinical improvement and discharge, and reduced admission rates in children presenting with moderate to severe acute asthma exacerbations (30). It is reported that ICS can be used as a replacement for OCS in treatment of acute asthma exacerbation in ED with comparable results $(27,28,31,32)$. Due to the side effects of OCS, the use of inhaled corticosteroids has increased turning them into the choice treatment of asthma $(28,33)$. It has been shown that inhaled corticosteroids improve lung function, asthma symptoms, and rescue inhaler use in patients with mild, moderate, and severe persistent asthma. They also reduce the need for oral corticosteroids in patients with severe persistent asthma and maintain asthma control (34).

In this randomized clinical trial, we evaluated the efficacy of treatment with inhaled fluticasone and OCS in mild to moderate asthma exacerbation in ED. We observe that oral prednisolone could more effectively improve patients' symptoms like cough, sputum and need for salbutamol as rescue inhaler in the first three days post exacerbation; however, the symptom free cases were comparable on the seventh day of evaluation. There was also a trend toward lower symptoms at night in inhaled fluticasone group which was not significant. Similarly, Schuh et al. (29) observed that children with mild to moderate asthma improve faster when given OCS compared to inhaled fluticasone.

To control the exacerbation, augmenting inhaled ICS doses (quadruple the dose of an ICS for 7 days) during asthma exacerbations (i.e. emergence of deteriorating symptoms) is recommended in addition to the initiation of inhaled b2-agonists in those who use ICS therapy (35-37); consequently the need for oral corticosteroids could be eliminated (31). Budesonide 200-400mg four times daily in combination with a beta-agonist at the first sign of asthma exacerbation have also been used (36). Consequently, throughout a 1 year follow-up, exacerbations were controlled in $94 \%$ of cases. High doses of ICS have occasionally been reported to be as efficient as systemic corticosteroids in the treatment of acute asthma exacerbations in children (25). In patients with mild to moderate asthma exacerbations, ICS administration with or without OCS recovers respiratory profile, decreases aminophylline infusion or systemic corticosteroid therapy requirement, precludes hospitalizations while leading to faster ED or hospital discharge $(25,38-40)$. ICS have been reported to be associated with further and more quickly improvement in asthma symptom scores than with OCS during the first week following discharge $(41,42)$.

We also observed that spirometry parameters especially FEV1, FVC and FEF 
significantly improve after 1 week in children receiving inhaled fluticasone compared to oral prednisolone. Similar results are reported in the literature $(28,40,43)$. It is reported that ICS transiently increases spirometric and clinical measures as early as 60 minutes (44). However, some studies also could not demonstrate beneficiary effects of ICS over OCS $(24,41)$.

\section{Conclusion}

In conclusion, both inhaled fluticasone and oral prednisolone improved symptoms during a week after exacerbation; however, the better respiratory function in children treated with inhaled fluticasone is indicative of the more efficacy of the therapy compared to oral prednisolone. Considering the low systemic effects of inhaled fluticasone compared to oral prednisolone, this treatment seems to be more appropriate in mild to moderate exacerbations.

\section{References}

1. Martinez FD. Trends in asthma prevalence, admission rates, and asthma deaths. Respir Care. 2008;53:561-5.

2. Akinbami L, Moorman JE, Garbe PL, Sondik EJ. Status of childhood asthma in the United States, 1980-2007. Pediatrics. 2009;123 Suppl 3:S131-45.

3. American Academy of Pediatrics Committee on Pediatric Emergency Medicine. Overcrowding crisis in our nation's emergency departments: is our safety net unraveling? Pediatrics. 2004;114(3):878-888.

4 Stang AS, McGillivray D, Bhatt M, Colacone A, Soucy N, Léger R, et al. Markers of overcrowding in a pediatric emergency department. Acad Emerg Med. 2010;17(2):151-156.

5. Bateman ED, Hurd SS, Barnes PJ, Bousquet J, Drazen JM, FitzGerald M, et al. Global strategy for asthma management and prevention: GINA executive summary. Eur Respir J. 2008;31(1):143-78.

6. Kling S1, Zar HJ, Levin ME, Green RJ, Jeena PM, Risenga SM, et al. Guideline for the management of acute asthma in children: 2013 update. S Afr Med J. 2013;103(3 Pt 3):199-207.

7. Mitchell EA. Consensus on acute asthma management in children: AdHoc Pediatric Group. N Z Med J. 1992; 105: 353-5.

8. National Asthma Education and Prevention Program. National Heart Lung and Blood Institute. Expert Panel Report 3: Guidelines for the Diagnosis and Management of Asthma. Bethesda, MD: National Institutes of Health; 2007. Vol 08-5846.

9. Lougheed MD, Garvey N, Chapman KR, Cicutto L, Dales R, Day AG, et al. Variations and gaps in management of acute asthma in Ontario emergency departments. Chest. 2009;135(3):724-736.

10. Rowe BH, Spooner CH, Ducharme FM, Bretzlaff JA, Bota GW. Early emergency department treatment of acute asthma with systemic corticosteroids. Cochrane. Database. Syst Rev. 2001;(1):CD002178.

11. Rachelefsky G. Treating exacerbations of asthma in children: the role of systemic corticosteroids. Pediatrics. 2003;112:382-397.

12. Scarfone RJ, Friedlaender E. Corticosteroids in acute asthma: past, present, and future. Pediatr Emerg Care. 2003;19:355-361.

13. Butler K, Cooper WO. Adherence of pediatric asthma patients with oral corticosteroid prescriptions following pediatric emergency department visit or hospitalization. Pediatr Emerg Care. 2004;20:730-735. 
14. Gamble J, Stevenson M, McClean E, Heaney LG. The Prevalence of Non-adherence in Difficult Asthma. Am J Respir Crit Care Med. 2009;180:817-22.

15. Beeraka SS, Natarajan K, Patil R, Manne RK, Prathi VS, Kolaparthi VS. Clinical and radiological assessment of effects of long-term corticosteroid therapy on oral health. Dent Res J (Isfahan). 2013;10(5):666-73.

16. Tse SM, Kelly HW, Litonjua AA, Van Natta ML, Weiss ST, Tantisira KG; Childhood Asthma Management Program Research Group. Corticosteroid use and bone mineral accretion in children with asthma: effect modification by vitamin D. J Allergy Clin Immunol. 2012;130(1):53-60.e4.

17. Busse W, Bleecker ER, Bateman ED, Lötvall J, Forth R, Davis AM, et al. Fluticasone furoate demonstrates efficacy in asthma patients symptomatic on medium doses of inhaled corticosteroid therapy: a randomised, placebo-controlled trial. Thorax. 2012;67:35-41.

18. Castro-Rodriguez JA, Rodrigo GJ. The role of inhaled corticosteroids and montelukast in children with mildmoderate asthma: results of a systematic review with meta-analysis. Arch Dis Child. 2010;95(5):365-370.

19. National Asthma Education and Prevention Program. Expert Panel Report 3 (EPR-3): Guidelines for the Diagnosis and Management of Asthma-Summary Report 2007. J Allergy Clin. Immunol. 2007;120(5 Suppl):S94-138.

20. Raissy HH, Blake K. As Needed Use of Inhaled Corticosteroids for Management of Mild Persistent Asthma in Children. Pediatr Allergy Immuno Pulmonol. 2011;24(4):231-233.

21. Bleecker ER1, Bateman ED, Busse WW, Woodcock A, Frith L, House KW, et al. Once-daily fluticasone furoate is efficacious in patients with symptomatic asthma on low-dose inhaled corticosteroids. Ann Allergy Asthma Immunol. 2012;109(5):353-358.e4.

22. Schuh S, Reisman J, Alshehri M, Dupuis A, Corey M, Arseneault R, et al. A comparison of inhaled fluticasone and oral prednisone for children with severe acute asthma. N Engl J Med. 2000;343:689-694.

23. Nakanishi AK, Klasner AK, Rubin BK. A randomized controlled trial of inhaled flunisolide in the management of acute asthma in children. Chest. 2003;124:790-794.

24. Manjra Al, Price J, Lenney W, Hughes S, Barnacle H. Efficacy of nebulized fluticasone propionate compared with oral prednisolone in children with an acute exacerbation of asthma. Respir Med. 2000;94(12):1206-14.

25. Volovitz B. Inhaled budesonide in the management of acute worsenings and exacerbations of asthma: A review of the evidence. Respir Med. 2007;101(4):685-95.

26. Razi CH, Turktas I, Bakirtas A. Comparison of single 2000-microg dose treatment vs. sequential repeated-dose 500microg treatments with nebulized budesonide in acute asthma exacerbations. Ann Allergy Asthma Immunol. 2008;100:370-376.

27. Ververeli K, Chipps B. Oral corticosteroid-sparing effects of inhaled corticosteroids in the treatment of persistent and acute asthma. Ann. Allergy. Asthma Immunol. 2004;92:512-522.

28. Nuhoglu Y, Bahceciler NN, Barlan IB, Mujdat Basaran M. The effectiveness of high-dose inhaled budesonide therapy in the treatment of acute asthma exacerbations in children. Ann Allergy Asthma Immunol. 2001;86:318-322.

29. Schuh S, Dick PT, Stephens D, Hartley M, Khaikin S, Rodrigues L, et al. High-dose inhaled fluticasone does not replace oral prednisolone in children with mild to moderate acute asthma. Pediatrics. 2006;118(2):644-50.

30. Zemek R, Plint A, Osmond MH, Kovesi T, Correll R, Perri N, et al. Triage nurse initiation of corticosteroids in pediatric asthma is associated with improved emergency department efficiency. Pediatrics. 2012;129(4):671-80.

31. Foresi A, Morelli MC, Catena E. Low-dose budesonide with the addition of an increased dose during exacerbations is effective in long-term asthma control. On behalf of the Italian Study Group. Chest. 2000; 117:440-446.

32. Schramm CM, Carroll CL. Advances in treating acute asthma exacerbations in children. Curr Opin Pediatr. 2009;21(3):326-32. 
33. Abdullah AK, Khan S. Evidence-based selection of inhaled corticosteroid for treatment of chronic asthma. J

Asthma. 2007;44:1-12.

34. Singas E, Karpel JP. Profile of ciclesonide for the maintenance treatment of asthma. Ther Clin Risk Manag. 2011;7:351-8.

35. FitzGerald JM, Becker A, Sears MR, Mink S, Chung K, Lee J, et al. Canadian Asthma Exacerbation Study Group. Doubling the dose of budesonide versus maintenance treatment in asthma exacerbations. Thorax. 2004; 59:550-556.

36. Volovitz B, Nussinovitch M, Finkelstein Y, Harel L, Varsano I. Effectiveness of inhaled corticosteroids in controlling acute asthma exacerbations in children at home. Clin Pediatr (Phila). 2001; 40:79-86.

37. Harrison TW, Oborne J, Newton S, Tattersfield AE. Doubling the dose of inhaled corticosteroid to prevent asthma exacerbations: randomised controlled trial. Lancet. 2004; 363:271-275.

38. Sung L, Osmond MH, Klassen TP. Randomized, controlled trial of inhaled budesonide as an adjunct to oral prednisone in acute asthma. Acad Emerg Med. 1998; 5:209-213.

39. Singhi SC, Banerjee S, Nanjundaswamy HM. Inhaled budesonide in acute asthma. J Paediatr Child Health. 1999; 35:483-487.

40. Devidayal, Singhi S, Kumar L, Jayshree M. Efficacy of nebulized Budesonide compared to oral prednisolone in acute bronchial asthma. Acta Paediatr. 1999; 88:835-840.

41. Volovitz B, Bentur L, Finkelstein Y, Mansour Y, Shalitin S, Nussinovitch M, et al. Effectiveness and safety of inhaled corticosteroids in controlling acute asthma attacks in children who were treated in the emergency department: a controlled comparative study with oral prednisolone. J Allergy Clin Immunol. 1998;102:605-9.

42. Milani GKM, Nelson A, Filho R, Riedi CA, Figueiredo BC. Nebulised budesonide to treat acute asthma in children. J Pediatr. 2004;80:106-12.

43. Rodrigo GJ. Comparison of inhaled fluticasone with intravenous hydrocortisone in the treatment of adult acute asthma. Am J Respir Crit Care Med. 2005;171:1231-1236.

44. Rodrigo GJ. Rapid effects of inhaled corticosteroids in acute asthma: an evidence-based evaluation. Chest. 2006;130:1301-1311. 